\title{
Innovation Research in Industrial Small Enterprise in Internet Era_-Based on the Survey Data of Ningbo of 2014
}

\author{
Jing Peng and Xingheng Xie \\ School of Economic and Management, Ningbo University of Technology, Ningbo, P.R.China, \\ 315211 \\ nbcpengj@sohu.com, Mary558@163.com
}

Keywords: Industrial small enterprise; Internet era; Innovation research; Survey data of Ningbo

\begin{abstract}
This paper, based on the survey data of Ningbo industrial small enterprises of 2014, analyzes the innovation of Ningbo industrial small enterprises and find that current industrial small businesses are generally lack of innovation, unable to meet the consumers' needs of Internet era, also can't compete with the companies of developed countries. This paper discusses the reasons for lack of innovation in the industry small enterprises, and the author puts forward that how the industrial small enterprises make technology and product innovation, management and business model innovation, and how to give the proper guide by government and cooperation by other social forces.
\end{abstract}

\section{Introduction}

With the advent of intelligent manufacturing and Industrial internet, developed countries implement the strategy of "Reindustrialization", start to focus on the domestic manufacturing industry. In 2012, National Science and Technology Council (NSTC) issued the "Advanced Manufacturing National Strategic Plan"; The German government officially launched the "German 4.0 Industrial Strategy" in April 2013, In September 2013, the French officially announced the implementation of "the French New Industries Plan"; In October 2013, the British Government's Office of Science and Technology, launched "The future of manufacturing: a new era of opportunity and challenge for the UK". At the same time, emerging countries pay more and more attention to the development of domestic industry, for example, India's prime minister, Mr Modi in August 2014 for the first time put forward the strategy of "made in India", think "India will overtake China as the next world factory". It is visible that both developed countries and emerging countries want to lead in a new round of industrial revolution, The Strategy is the integration of their manufacturing and the Internet 。Thus, China's industry is facing the double-pronged attack: on the one hand is the developed countries in the areas of high-end manufacturing have first-mover advantage, Such as talent advantage, technology advantage and market advantage etc, so they Take a number of commanding heights of the high-end industries and emerging industries, posing a big pressure on Similar industrial development of our country. India and Southeast Asia and other developing countries, on the other hand, using their own labor advantages attract labor-intensive industries transfer, posing a big pressure on low-end industrial development of our country .

In July ,2015 the State Council promulgated" the Action Guidance on the actively promote the Internet +"marks the era of the Internet to come true. In March, 2016 the government work report proposed; we should promote the "Made in China + Internet" further. This shows that the effects of connecting the Internet are increasingly penetrating into the manufacturing industry in China. In May, 2016 the State Council issued "on the manufacturing industry and the integration of the Internet development guidance", the double drive strategy of "Internet+" and "China manufacturing 2025 " started, pushing traditional manufacturing industry innovation and transformation. Especially for the innovation of traditional industrial small enterprise has brought unprecedented opportunities.

Ningbo industrial has been the main engine of Ningbo sustained economic growth, At present, there is a good development foundation of Ningbo industry, and Ningbo is the first pilot and demonstration area in "Made in China 2025 strategy". The industrial small businesses are an 
important force in Ningbo economic and social development, playing an increasingly important role to promote Ningbo science and technology innovation. The industrial added value is 346.09 billion 1CNY in 2015 in Ningbo, rose only 4.4\% than 2014, lower than the rate of increase in 2014.But the growth of small business industrial added value is $7.3 \%$, nearly $4 \%$ higher than that of large enterprises. In addition, the number of Ningbo industrial small business accounting for $52.7 \%$ of the Ningbo industrial workers, i.e. 1.321 million, much higher than the other types of industrial enterprise staff number ; Ningbo industrial small enterprise total assets, respectively, $25.4 \%$ more than large-sized industrial enterprises and $10.3 \%$ more than medium-sized industrial enterprises. The revenue is higher than large and medium-sized enterprises, respectively, $15.9 \%$ and $15.2 \%$.Thus, Ningbo industrial small total scale is very big, and is the important part of the Ningbo industrial development, made considerable contributions for the development of Ningbo industrial.

\section{Current Innovation Status of Ningbo Industrial Small Enterprise}

Technological Innovation Situation. Technological innovation is the cornerstone of enterprise development, the production equipment which is the foundation of technological innovation. According to the survey, as shown in Fig. 1, more than half of the Ningbo industrial small enterprises think their main production equipments are only domestic average level.36.0\% of the enterprises think their main production equipments have reached advanced domestic level, there are only $4.8 \%$ of the industrial enterprises' main production equipments have reached the international advanced level. Although Ningbo industrial developed rapidly a few years ago,, but the technical content is not high. Momentum is largely due to the geographical advantages and export-oriented economy. In the gradual loss of these advantages, the technology innovation of Ningbo industrial small enterprises is urgently needed.

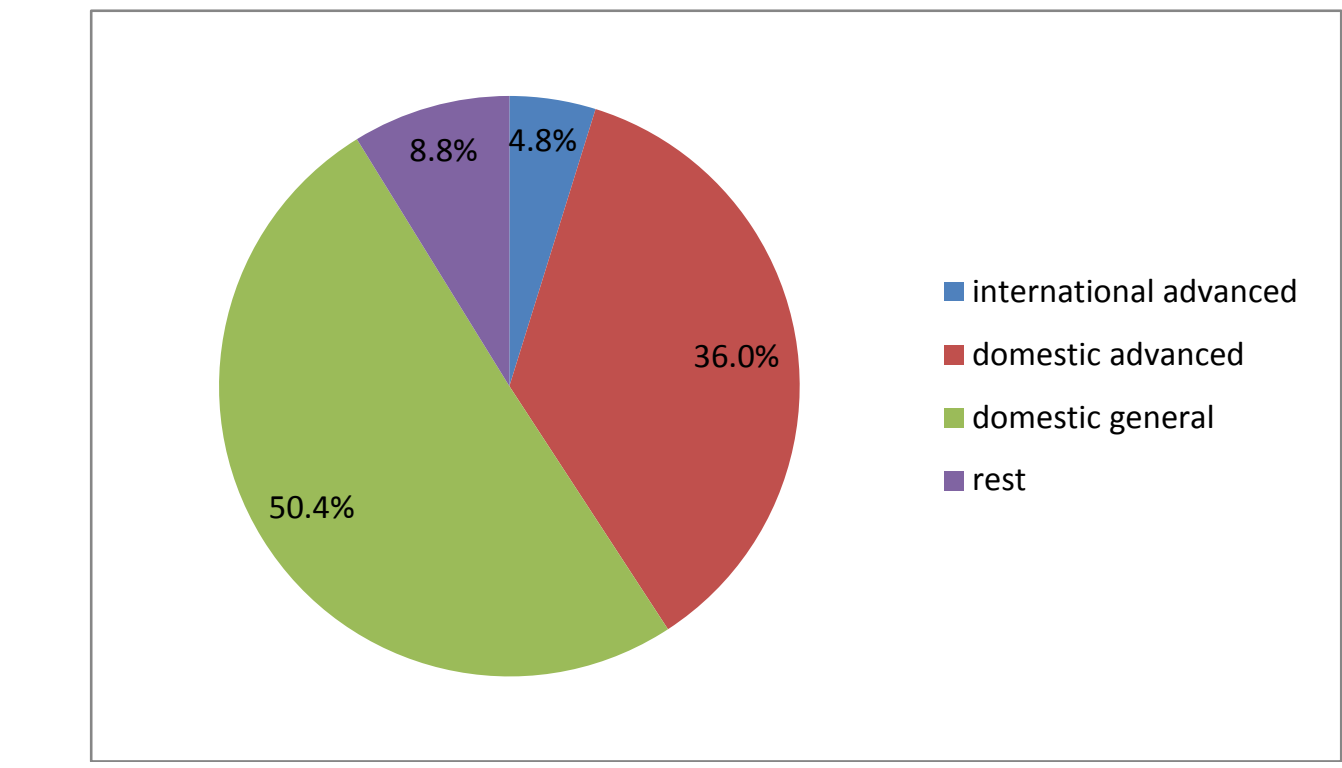

Figure 1. The technology level of production equipment of Ningbo small industrial enterprises in 2014

In terms of specific innovation of small business, in addition to the $6.2 \%$ of Ningbo industrial businesses think there isn't any innovation in 2014 and $2.5 \%$ of the enterprises to choose the option of " rest", all the other enterprises have carried on one or several aspects of innovation.68.7\% of the Ningbo industrial small business developed new products on the basis of the existing product line in 2014 . Choose to develop a new product line, by contrast, is the lowest proportion of Ningbo industrial businesses, only $28.7 \%$.( Fig. 2)Investigate its reason, the author thinks that on the one hand, because of the large capital input for the development new product line, many small 
businesses don't want to or unable to bear; On the other hand, the level of technology development of the small business is not high enough, strength of R\& D needs to be strengthened.

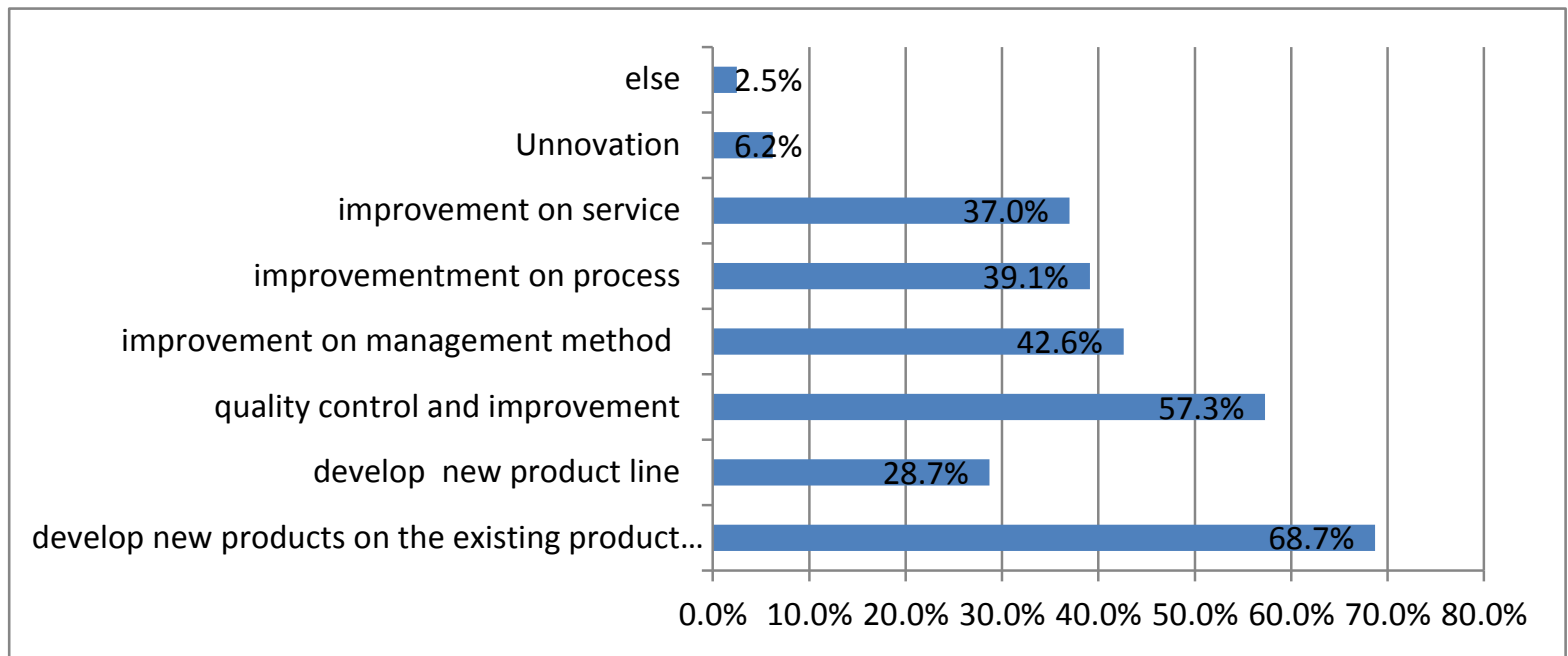

Figure 2. Innovation in Ningbo industrial small enterprise in 2014

Product Innovation Status. About the new products development of Ningbo industrial small businesses, as shown in Fig. 3, the number of enterprises which develop new product less than 5 pieces is the largest, the proportion is $42.6 \% .24 .3 \%$ of the enterprise developed 6-10 new products, $11.1 \%$ of companies developed 10-20 new products, $12.1 \%$ of companies reached more than 20 new products in $2014.9 .9 \%$ of companies said there is no new product development.

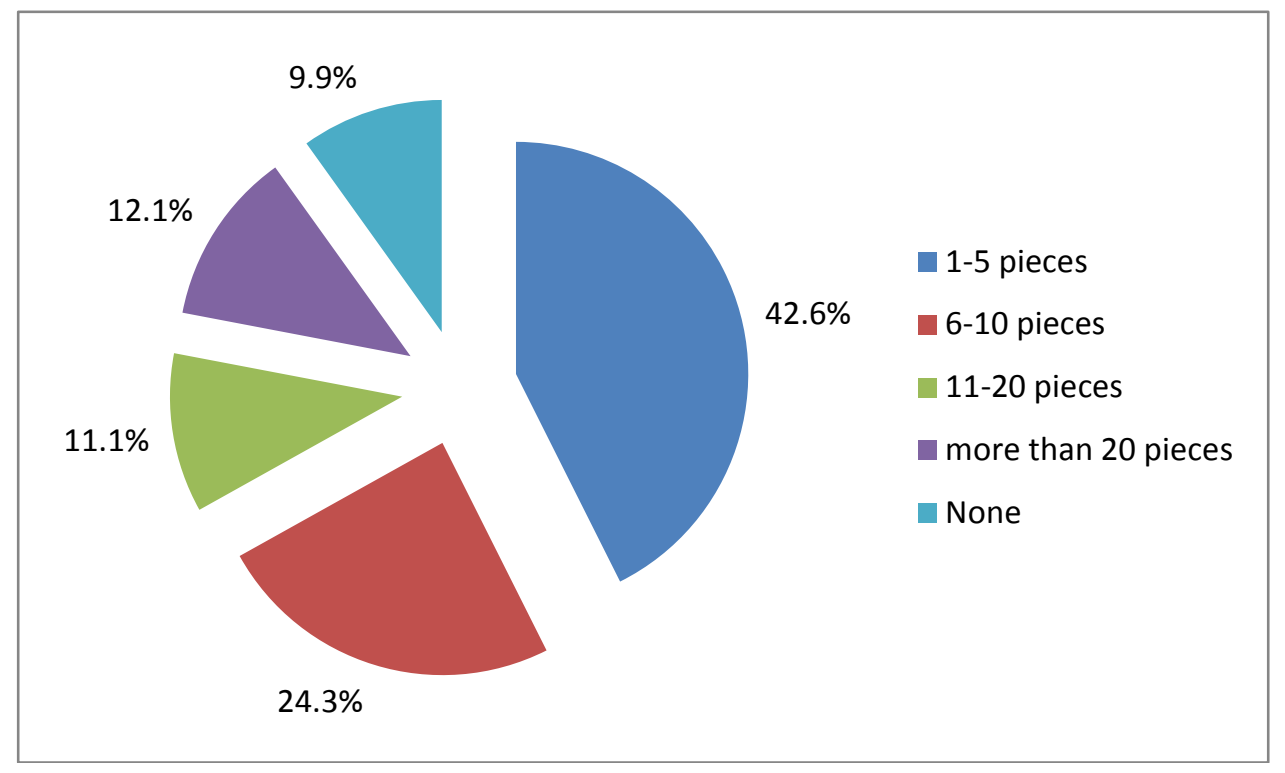

Figure 3. Number of new product development in Ningbo industrial small enterprise in 2014

It is shown in Fig. 4, these new products bring the income share of revenues in the enterprise. 168 of small business said the $6 \%-10 \%$ of total revenue brought by new product, i.e. $47.6 \%$ of the sample enterprises. Followed by $33.5 \%$ of small businesses, said new products bring income the proportion of total income of enterprises accounted for $5 \%$ and below. New products bring income in corporate revenues accounted for $20 \%$ to $40 \%$ or even more than $40 \%$ of the enterprises is the proportion of $15.7 \%$ and $3.2 \%$, respectively. 


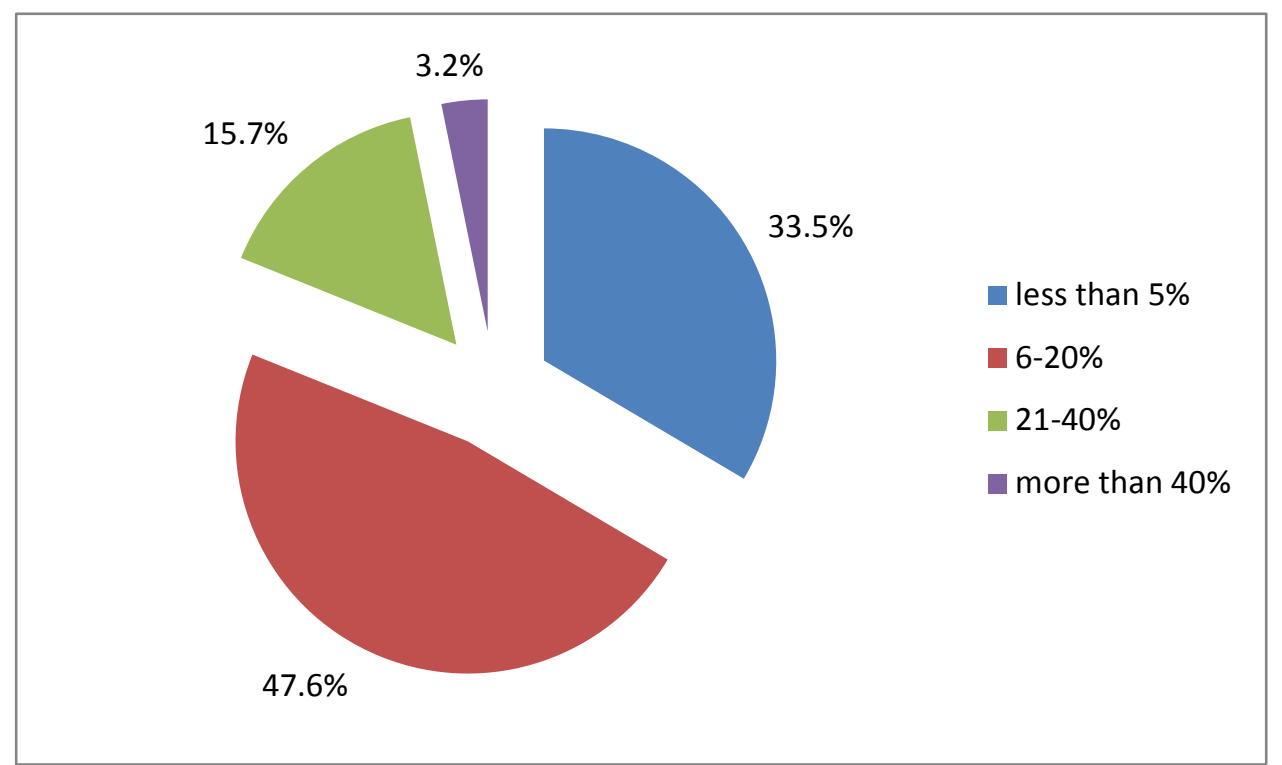

Figure 4. New product revenue share of total revenues in the enterprise in 2014

In addition, in 2014, the number of industrial small enterprises whose industrial R\&D expenditure accounts for $6 \%-10 \%$ of the sales revenue is the most,i.e. $41.6 \%$..Followed by R\&D expenditure below $5 \%$ of sales revenue, at $39.2 \%$, the difference is not big. Only $19.2 \%$ of the industrial $\mathrm{R} \& \mathrm{D}$ expenditure is higher, reached more than $10 \%$ of sales revenue of small enterprises. Overall, the expenditure of technology innovation of Ningbo industrial small enterprises is few, and new product development is less, thus brings limited income to enterprises. (Fig. 5)

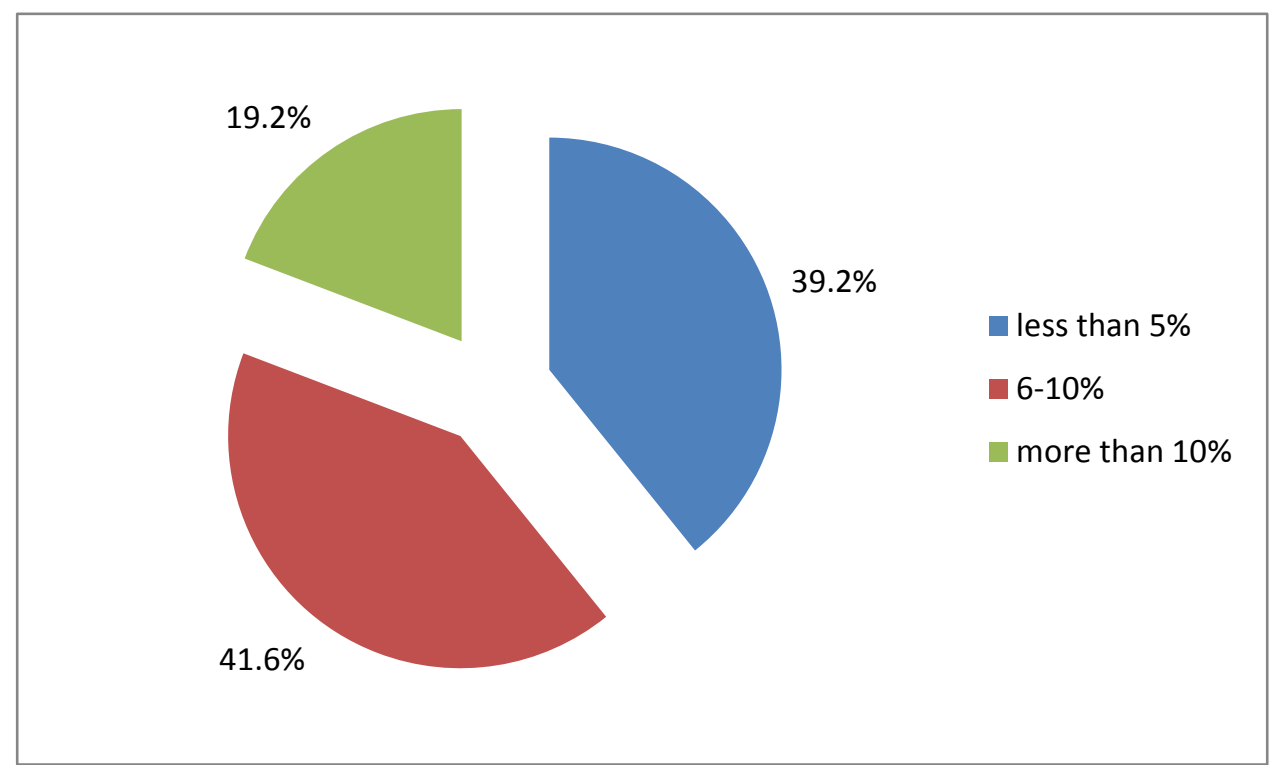

Figure 5. R\&D expenditures of Ningbo industrial small enterprise accounts for the proportion of sales revenue in 2014

Human Resource Condition Needed by Small Enterprise Innovation. Enterprise innovation design and implement by human, so, human resources condition is directly related to enterprise innovation. Enterprise management personnel, especially the degree and quality of top management is one of the decisive factors of enterprise innovation. As shown in Fig. 6.,among the small enterprises we survey, $58 \%$ of top management's degree is college or university, the largest proportion.6\% of small businesses senior management education for master degree and above. The remaining $36 \%$ of the small enterprise senior management personnel are not trained in higher education, of which $31 \%$ of small businesses senior management degree for senior high school or technical secondary school, $5 \%$ of small businesses senior management personnel qualifications for junior middle school or below. We think the low degree of top management, to some extent, 
affected the enterprise's technology innovation and management innovation.

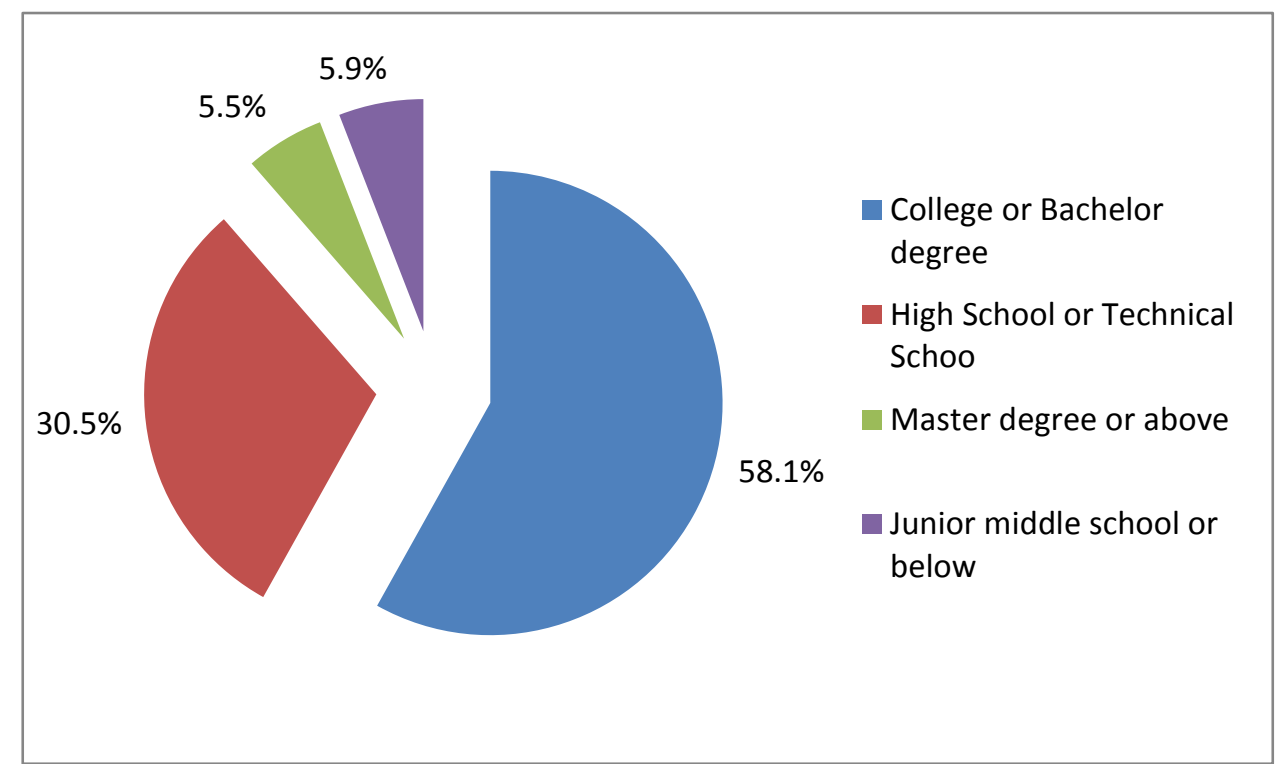

Figure 6. Education background of senior management in Ningbo industrial small enterprise

We also found in the investigation, as shown in Fig. 7, Ningbo industrial small businesses lack most is R\&D personnel.71.2\% of the industry said it is the most difficult to find R\&D personnel to small business. Which on the one hand, account for the technology level is generally low, so the technology research and development personnel are needed. On the other hand, small businesses already more and more emphasis on the development of new products, new technology research. But because of a shortage of funds and technology personnel resources, the enterprise technology upgrades and new product development is very weak.

In addition, the Sales management personnel is the most difficult to find . $44.7 \%$ of small businesses express the lack of sales management talent. Maybe it's just because of product homogeneity between small enterprises, so it is difficult when sell those products in the market. The effective sales management talent is needed urgently. In addition, in the Internet age, all kinds of electricity sales patterns such as B2C, B2B, etc emerge in endlessly, many small enterprises sell their products from offline to online sales, they all need professional sales management talent due to the fierce market competition.

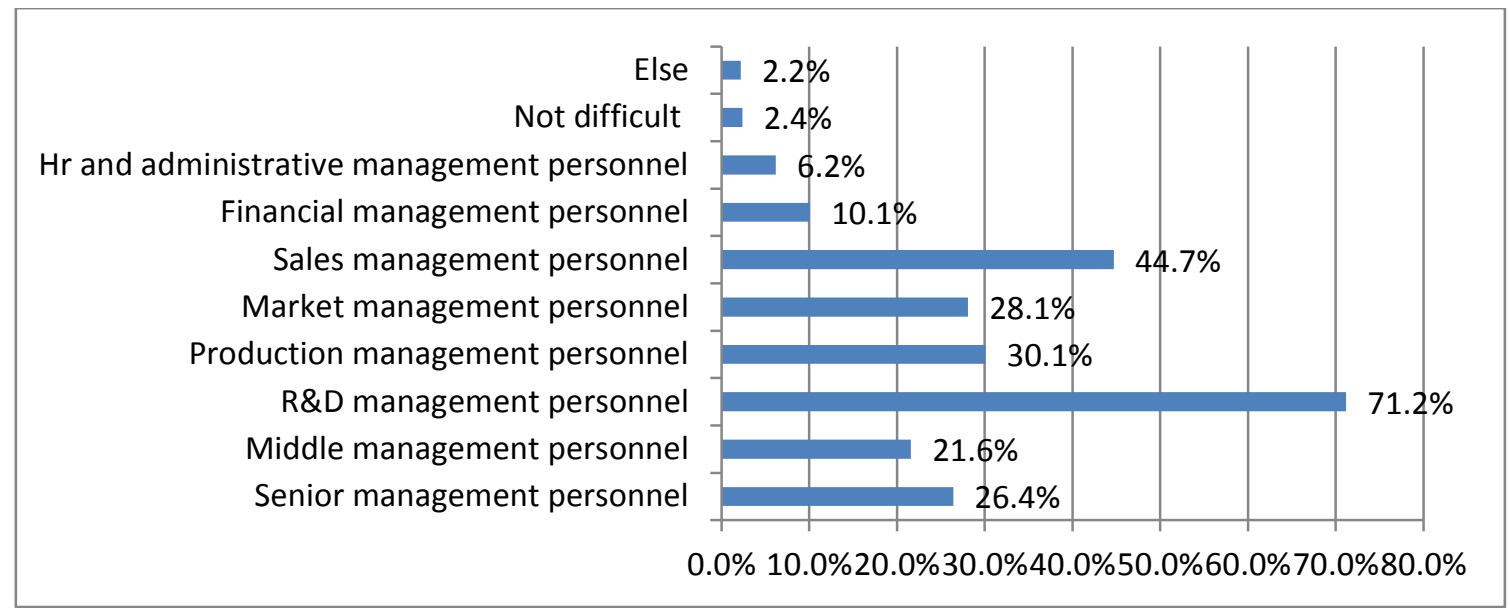

Figure 7 Personnel that is the most difficult to find in Ningbo industrial small enterprise

Enterprise management innovation. So far, many industrial Ningbo small enterprises use the 
Internet in the sales process, besides, they also use the Internet in the enterprise management more or more. According to the survey of the research, as shown in Fig. 8, the main purpose of $26.0 \%$ and $25.2 \%$ of Ningbo industrial small enterprises are using the Internet for market information and corporate propaganda respectively. And $20.1 \%$ of small businesses have developed e-commerce by using the Internet, the proportion is not high. Only $13.3 \%$ of small businesses use the Internet to establish modern management system, the proportion is the minimum. Thus, To Ningbo industrial small business management, the integration of the Internet is not enough, it is necessary to them to enhance the consciousness and make an action, using the Internet to improve the company's management level and manufacturing technology level.

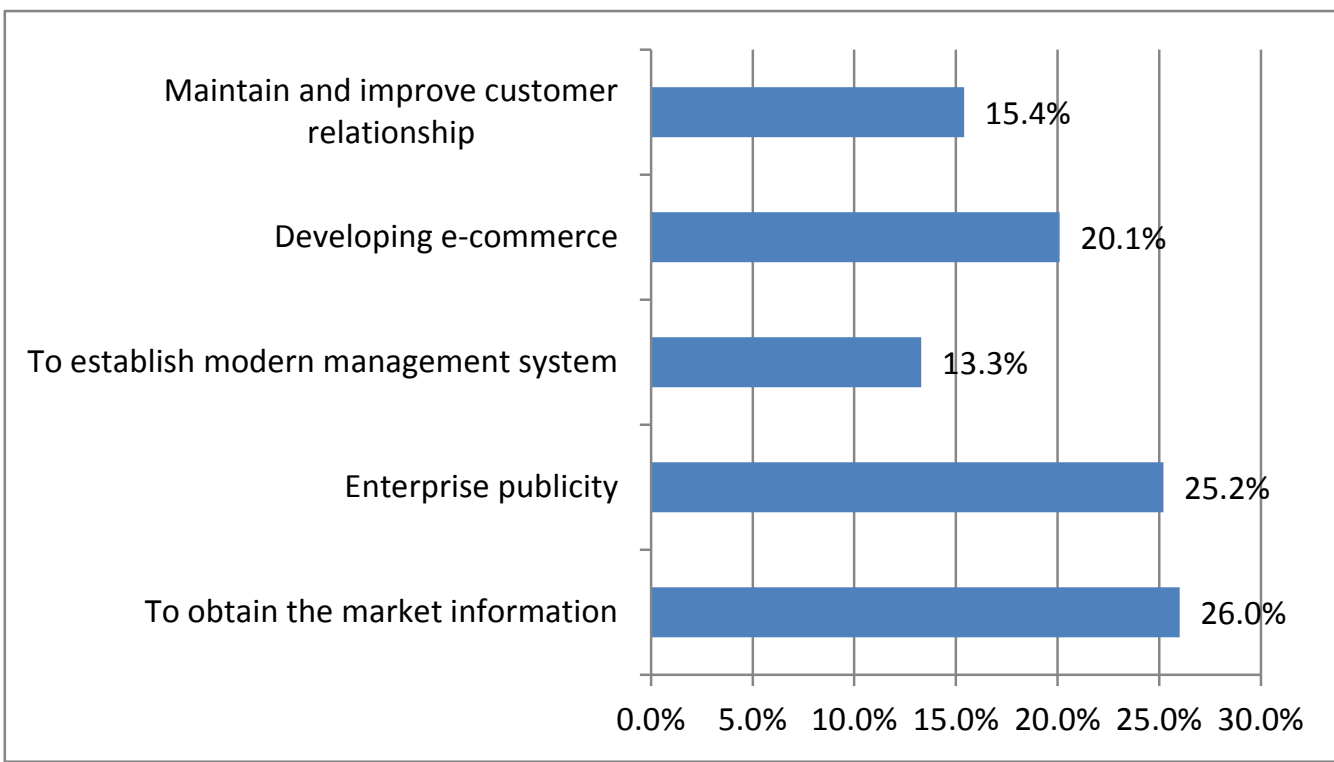

Figure 8. The main purpose of using the Internet in Ningbo industrial small enterprise

\section{Analysis of the Causes for Insufficient Innovation in Industrial Small Enterprises}

Most Industry small enterprises focus in the production of daily necessities, such as plastic products, home appliances, garments, light industry, etc.. Now these areas are basically excess capacity. Low value-added products, inventory backlog, rough quality, lack of technical content and independent design is the common situation to many industrial small enterprises. From R\&D expenditures, the development of new products or the choice of enterprise innovation are reflecting that there is not enough enthusiasm and initiative to the industry small enterprises at present to carry out technology development and innovation. And, in new product development, the survey found that the current industrial small enterprises are lack of thought of sustainable development. Many new product development of industrial small enterprises always depend on the government or scientific research organizations, or the relatively mature technology, or enjoying the technology spillover effect. They'd like to introduce or learn technology developed by other company, almost no own independent new technology. Some small firms would like to imitate because of less investment and quick effect. There are many causes of this situation, mainly display in three aspect:

Insufficient Expenditures for Innovation. Although small and medium-sized enterprise demand for money is not very lack in the investigation, but small business's savings is normally only enough for the day-to-day running of company. If the company plan to carry on the technological development and innovation, a lot of money is indispensable. Many enterprises need to other capital sources such as bank loans, but it is difficult to get a loan from the bank for technology innovation for small businesses. At the same time, it is also difficult to obtain technological development funds from the capital market for small businesses. And the government, although set up a number of funds to support small and medium-sized enterprise innovation 
activities, but these funds are typically used to support the larger medium-sized enterprises, financial support to small business is relatively more difficult 1 . And because the big gap between the demand and supply of capital to small enterprises, so the current fund supplied by government for solving the problem of technology innovation investment is also a drop in the bucket and the effect is not so good. In addition to the technological innovation needs money, small business management innovation or marketing mode innovation also need more money. Thus give large pressure to small businesses.

Lack of Relevant Talents. In the investgation, $71.2 \%$ of Ningbo industry small enterprises said that the technical development personnel is the most urgently needed talent for their companies, much higher than the demand for other talents. The lack of technology development talent is the key to restrict small enterprise technology innovation. Because of lack of sustainable development, small businesses can't foresee the long-term interests brought by technology innovation talents, and don't attach importance to talent training and reserves, training for the existing talent is not enough, too. some technical personnel feel that there's no scope for their energies and choose to leave small businesses. Some technical personnel's level is not high, the deep research in production process is not enough, and they can't put forward the technical improvement and innovative solutions. In addition, small businesses are lack of high level management personnel who also understand the Internet business.

Deficiency of Createing an Environment of Innovation. At present, although multiple innovation incubation centers have been set up all over the country, raise the guidance and services for small enterprises technology innovation. But the consultation, technology, science, law service system construction needed by technology innovation is not perfect enough. And, in recent years, although our country promulgated "the small and medium-sized enterprise law of the People's Republic of China", "Policy Suggestions about encouraging the development of small and medium-sized enterprises" and etc., which promote technology development and innovation of small businesses . But compared with developed countries, the current intellectual property policy environment in China is still not perfect, intellectual property policy related to the protection of small and medium-sized enterprise is lack relatively, the phenomenon of infringement of intellectual property rights are still prominent. For enterprises, they cost highly to apply for a patent or other intellectual property rights, and have to not only spend much money and time to complete the relevant application process. but also bear the opportunity cost of failure of application for a patent .When enterprise's intellectual property rights are infringed, cost in safeguarding the rights and interests is very high. So a lot of small businesses reluctant to technology development and innovation, some boss of small enterprises even argue that technical innovation will lead to decline in corporate profits or other adverse effects.

\section{Main Countermeasures}

In the face of a new round of global industry changes and the domestic "new normal" economy, low value-added products, low cost operation is unsustainable for industrial small enterprises, and the only way out is the initiative innovation to get more development space. In the process of innovation, small enterprises should actively meld with internet in depth, with the help of intelligent manufacturing, make technical innovation and business model innovation collaboratively. At the same time, the construction of innovative environment as well as the appropriate guide by relevant administrative department is indispensable.

Make full Use of Internet for Products and Technology Innovation. The main goal of industrial businesses actively meld with the Internet is to promote the efficiency of implementation, and strengthen the competitive power of the enterprise, get rid of the situation of value-added chain in the low end.. Industry i small enterprises should strengthen the consciousness of innovation and knowledge acquisition, internalization and innovation ability. With the continuous development of information technology, industrial small businesses can use Internet to achieve technical innovation. The enterprises produce same products or upstream and downstream of industrial cluster can make up an innovation alliance, or collaborative innovation with the help of the platform, which is the 
best choice of industrial small enterprises at present.

As the industry division of labor increasingly refined, product complexity growing substantially expand the breadth and depth of technology integration, a single company cannot cover all innovation, they should form a new type of synergy innovation network with universities, scientific research institutions, industry associations and other enterprises .Conditional small businesses can set up R\&D department and introduce or cultivate the enterprise's senior technical talent, actively looking for opportunities to participate in the enterprise's technical innovation alliance, by integrating the excellent technical resources, transforming the current disadvantage of labor cost into advantage of technical support, shifting away the simple processing of high cost, wasting resource, low output value industry. Develop high technical content of products or to undertake high-end processing industry and proposed the construction of the enterprise independent brand strategy. Thus gradually occupy a more favorable position in the industry chain and in collaborative innovation system, to realize profit maximization.

In addition, industrial small businesses can make full use of the Internet's unique advantages to improve enterprise manufacturing efficiency. They can learn about the latest technology and equipment through the Internet, combine industrial Internet and intellectual technology in consideration of their own situation and industry technology, using network technology to realize intelligent control of the manufacturing process, make efforts to intelligent manufacturing, thus improve the product quality, reduce manufacturing cost and the enterprise operating costs, achieve the transformation and upgrading of the enterprise. In fact, the integration of the Internet and the industry small business is especially suitable for the consumption mainstream of our era. Unlike traditional mass production, now the market consumption tends to individuation, diversification, thus the enterprise also tend to be more miniaturization, intelligent and specialized production. If, as a result, small businesses can focus on small and specialized production mode, will be very beneficial to finding their own market segment and customer demand, making product improvement, implementing products and technology innovation in the market environment of continuous and unanticipated change.

Make full Use of Internet for Management and Business Model Innovation. Industrial small enterprise should make full use of the Internet to improve management level, to establish modern management system. They should establish efficient production and administration management system by learning or sending staff to attend training. They should understand the industry technology development closely, focus on the change of market demand and make product improvements timely, seize market opportunities. They can also make use of Internet to construct and manage their own brand, inventory logistics and etc.

In addition, industrial small enterprises should also pay attention to business model innovation which focus on market orientation and user experience, make technology innovation achievements transform into actual business value faster. Ningbo Cixi small household appliance enterprises jointly hold together to build the Cixi electrical appliances pavilion, they draw into many domestic and foreign big electric business platform, build word-of-mouth in the form of regional industry cluster on the Internet. And the electrical appliances pavilion enrich product sales channels for their members, and expand the market, reduce the marketing costs, many companies benefit from it. Beyond that, they are also explore designing and manufacturing small household appliance products according to the needs of users, and promoting on the Internet, establishing overseas warehouse, making the cixi electrical appliances product send to the user at a lower logistics cost. These business model innovation is worthy of reference and learning. for other industrial enterprises.

Proper Guide by Government and Cooperation by Other Social Forces. Industrial small enterprises should adapt to the market demand to make innovation. They also need the government's guidance and the help of other social forces to carry out the government's preferential policies to foster a sound environment for innovation.

From the policy aspect, our country have ascended the work of upgrading SMEs to a height of a strategic task. From the promulgation of the "SME promotion law", to all kinds of preferential fiscal 
and taxation policies formulated by the last two years, are measures of decentralization by government, activating the vitality of small and medium-sized enterprise. Local governments also did a lot of work, such as establishing 2015 special action implementation scheme to small and micro enterprise in Ningbo, striving to resolve outstanding difficulties and problems in the development of enterprises. However, Ningbo, investigation of the implementation of the preferential policies by 8718 small and medium-sized enterprises public service platform show that many small businesses do not fully know these preferential policies, which appear in the asymmetry of information. The policy of unemployment insurance allowance for micro, small and medium enterprises, for example, only $8 \%$ of companies say they enjoyed the policy. The remaining $92 \%$ of the enterprises, some are not eligible to apply for ,many enterprises don't know the policy .Therefore, besides implementing more reasonable policies to reduce the financial burden of small businesses, more important thing is to make the government's preferential policies should be conscientiously implemented to the enterprises which real need them.

Second, various aspects social force should help industrial small enterprises more, such as encouraging commercial Banks to strengthen the financial services for industrial small enterprises, continued perfection of industrial small entrepreneurial base construction. They would also vigorously promote the construction of small micro enterprise of industrial concentration area and put them into use, help enterprises to implement the transformation and upgrading. Lead all kinds of venture investment funds to invest in small businesses, encourage universities, research institutes, engineering center open and share all kinds of experimental facilities to small businesses.

Third, various aspects force should continue to strengthen the construction of industrial integrated service system for small business, improve the network of enterprises public service platform, set up the mechanism of information connectivity, provide professional services such as entrepreneurship, innovation, finance, consulting, training, talents and etc. to all the industrial small enterprises.

Finally, the government has a responsibility to create a good market competition atmosphere, guide the small enterprises to adapt to information economy, face to face with the domestic new normal economy. With the help of various aspects social force, industrial small enterprises become an important innovation power of the Internet age through their own exploration and study.

\section{Acknowledgements}

Supported by the Zhejiang Federation of Humanities and Social Sciences Circles (Grant No. 2017N88) and the Ningbo Federation of Humanities and Social Sciences Circles (Grant No. JD15QY03)

\section{References}

[1] X.X.Chen, Research on Network Marketing Strategies of Small and Medium-Sized Enterprises in China ( MS, Huazhong University of Science \& Technology,2012) (In Chinese)

[2] G. X. Lin, Q. Gong, New Thinking on The Transformation and Upgrading of Traditional Manufacturing Industry Under The Background of Industry 4.0 ,Shanghai Economic Research, (2015) No.10,p107-113 (In Chinese)

[3] V. Martinez and M. Bastl: Challenges in Transforming Manufacturing Organizations into Product-service Providers, Journal of Manufacturing Technology Management, Vol. 21(2010), No. (4),449-469.

[4] T.Baines and H. Lightfoot: Towards an operations strategy for product-centric servitization, International Journal of Operations \& Production Management, Vol.29 (2009), No. (5), 494-519. 